Original Article

\title{
Protective nature of nano-TiN coatings shaped by EPD on Ti substrates
}

\author{
C. Mendoza ${ }^{\mathrm{a}, \mathrm{b}}$, Z. Gonzalez ${ }^{\mathrm{b}, *}$, E. Gordo ${ }^{\mathrm{c}}$, B. Ferrari ${ }^{\mathrm{b}}$, Y. Castro $^{\mathrm{b}}$ \\ a Nanomaterials, Catalysis and Electrochemistry, B-4000, Liège, Sart-Tilman, Belgium \\ b Instituto de Cerámica y Vidrio, CSIC, c/Kelsen 5, 28049, Madrid, Spain \\ c Departamento de Ciencia e Ingeniería de Materiales, Universidad Carlos III de Madrid, Avda. de la Universidad 30, 28911, Leganés, Spain
}

\section{A R T I C L E I N F O}

\section{Keywords:}

$\mathrm{Ti}$

TiN

Colloidal processing

Electrophoretic deposition

Protective behavior

\begin{abstract}
A B S T R A C T
The hardness and corrosion resistance of TiN coatings, processed by Electrophoretic Deposition (EPD) to cover polished and unpolished Ti substrates, have been evaluated. A deposition time of 5 min has been enough to obtain a cohesive layer of $7-8 \mu \mathrm{m}$ in thickness. The coatings were thermally treated in vacuum atmosphere at $1200{ }^{\circ} \mathrm{C}$ for $1 \mathrm{~h}$ with heating and cooling rates of $5^{\circ} \mathrm{C} \mathrm{min}{ }^{-1}$. The surfaces have been covered homogeneously optimizing the properties of the Ti substrates. Uniform and dense TiN coatings have been obtained onto polished substrates, while on unpolished Ti the nitrogen diffuses toward the substrate, moderately dissolving TiN coating. The nanohardness values of the polished samples have been increased from $2.8-4.8 \mathrm{GPa}$ up to 6.5-8.5 GPa. Besides, the corrosion current density has been reduced more than one order of magnitude obtaining a protective efficiency of $82 \%$. These values have been compared with other works in literature where authors used complex and costly processing techniques, demonstrating the strong impact of the colloidal processing over the specific properties of the material.
\end{abstract}

\section{Introduction}

$\mathrm{Ti}$ and $\mathrm{Ti}$ alloys have attractive properties such as high specific strength, biocompatibility, low density and corrosion resistance, being key compositions in aerospace, marine, biomedicine and industrial engineering applications [1,2]. Ti-based materials are bio-inert and they are frequently used in biomedical devices to replace heart valves, joints and bones. In this application the most relevant limitation of $\mathrm{Ti}$ and $\mathrm{Ti}$ alloys is their low bioactivity and poor tribological properties, such as poor fretting behavior, wear resistance and high coefficient of friction [3]. In biomedicine as well as in other applications, the surface microstructure modification and/or coating have been assessed as strategies to improve the surface properties of Ti alloys. Physical and chemical vapor deposition (PVD and CVD) have been explored as coating processes to produce ultra-hard films on Ti alloys [4-6], but also recently other processes as DC reactive magnetron sputtering $[7,8]$, electrodeposition [9], nitriding [10], laser surface treatment [11], solid state diffusion [12] and ion implanting [13], have been also proposed. Most of those techniques are limited by requirements of "atmosphere" or "pre-placement", complexity or high cost, making these processes difficult to implement in practice. In this sense, the look for non-expensive methods to shape hard coatings is still challenging.

Colloidal processing includes promising techniques for coating comparatively cheaper and based on a safe and healthy living environment technology. Those techniques are widely employed in ceramics since they have been probed to provide a high control over the resulting microstructures [14,15] throughout the manipulation of the particles dispersion maintaining the interparticle repulsion networks and then the suspension stability. Among the different colloidal processes, the Electrophoretic Deposition (EPD) is the most suitable one especially when we are dealing with the coverage of 3D and complex shapes. It consists in the electrophoretic movement of charged particles in a stable suspension and their deposition onto a conducting substrate. EPD has been widely implemented in both the academic and the industrial sector due to the simplicity of the apparatus and the short shaping times needed to complete the coating process. Moreover, EPD allows nanostructures tailoring and strengthening the control over the microstructure of 3D coatings [16]. The films thickness and the amount of the deposited mass can be easily tuned and controlled varying the concentration of the suspension, the applied potential or the deposition time [17].

Among ultra-hard ceramics, $\mathrm{Cr}$ and Ti-based nitrides ( $\mathrm{CrN}, \mathrm{CrAlN}$, TiN, TiAlN, etc.) and borides (TiB) [18] as well as TiN mixtures with different alloys (NiTi, FeNi) [9] are extensively considered in the literature as Ti coatings, as monolayer or even in multilayer systems (i.e. TiN/AlN, TiN/TiCN) $[5,19,20]$, to improve the surface toughness and corrosion properties. Results show that surface texturing of the Ti-based substrates plays an important role to prepare anti-wear coating with

\footnotetext{
* Corresponding author

E-mail address: zgonzalez@icv.csic.es (Z. Gonzalez).
} 
good adhesion, high toughness, hardness or low coefficient of friction. The mechanical response of TiN coatings yielded the decrease of the coefficient of friction while nanohardness ranges 7-18 GPa for surface nitriding, PVD and sputtered coatings $[7,10,21]$ and Vickers hardness measured for laser cladding coatings achieved 500-1000HV1.0 where its variation depends on the amount of deposited TiN [22].

On the other hand, corrosion studies of TiN coatings on Ti-based substrates are not frequently found in the literature. In 2013, Pohrelyak et al. [10] reported the relationship of the sample roughness with the corrosion resistance in a Ringer solution for the modified surface of a Ti alloy by nitriding. In recent published works, corrosion results in different test solutions $(\mathrm{HCl}$ or $\mathrm{NaCl}$ ) shows that the resistance of nitrides (TiN, TiAlN, CrN, CrAlN) depends on the coating composition and the number of layers, increasing the resistance efficiency in $\mathrm{NaCl}$ up to the $86.11 \%$ for CVD coatings in stainless steel $[8,23]$.

Thereby, the objective of this work is to evaluate the hardness and corrosion resistance of TiN coatings processed by EPD to cover Ti substrates, considering that it is a simple shaping process to obtain coatings with good adhesion properties [24,25]. In previous works[24], the preparation of TiN nanoparticle $(\sim 30 \mathrm{~nm})$ suspension and its further electrophoretic deposition on stainless steel and Ti substrates were reported. The advantage of the use of nanoparticles to shape those coatings is their lower sintering temperature, which allows the consolidation of dense gold-like TiN films of $10-20 \mu \mathrm{m}$ on stainless steel substrates and $5 \mu \mathrm{m}$ coatings on Ti specimens after a thermal treatment of $1200{ }^{\circ} \mathrm{C}$ in vacuum atmosphere. In the present manuscript, the crystallographic and microstructural characterization of optimized EPD coatings of TiN was firstly discussed, and further improvements on the mechanical response and the corrosion resistance of TiN/Ti materials compared to that of $\mathrm{Ti}$ bare-surface were determined.

\section{Materials and methods}

\subsection{TiN suspensions and EPD process}

As-received commercial TiN nanopowder (Hefei Kaier Nanometer Energy \& Technology, China) with a mean particle size of $30 \mathrm{~nm}$ was used to prepare the suspensions following a previously reported process [26]. A TiN suspension $\left(0.1 \mathrm{gL}^{-1}\right)$ was prepared using isopropyl alcohol (99.7\%, Panreac, Spain) as solvent and $1.5 \mathrm{wt} . \%$ of polyethylenimine (PEI, Sigma-Aldrich, Germany) as stabilizer. Mechanical stirring and sonication (Ultrasonication Probe, UP 400S, Hielscher, Germany) were used as dispersing methods to break the soft agglomerates of TiN nanoparticles.

Ti substrates of $15 \mathrm{~mm}$ of diameter and $0.5 \mathrm{~mm}$ of height were processed by uniaxial pressing at $600 \mathrm{MPa}$, and then sintered in vacuum atmosphere at $10^{-5} \mathrm{mbar}$ at $1050^{\circ} \mathrm{C}$ for $2 \mathrm{~h}$ with heating and cooling rates of $5{ }^{\circ} \mathrm{C} \min ^{-1}$ [26]. The sintered Ti substrates were polished using alumina suspensions $(9,1$ and $0.3 \mu \mathrm{m})$.

TiN films were shaped from nanoparticle stabilized suspensions by EPD on as-prepared and polished sintered Ti substrates. The counter electrode in the electrophoretic cell was a Pt foil of $2 \times 2 \mathrm{~cm}$, separated from the work electrode by a distance of $2 \mathrm{~cm}$. EPD was optimized and studied specimens was performed under galvanostatic conditions using a high voltage power source (2611 System SourceMeter, Keithley Instruments Inc., USA) applying current densities of $0.2 \mathrm{~mA} \mathrm{~cm}{ }^{-2}$ (voltage up to $90 \mathrm{~V}$ ). TiN coatings of $0.8-1 \mathrm{mg} \mathrm{cm}^{-2}$ were shaped on Ti substrates. After EPD, coatings were dried at room conditions and thermally treated in vacuum atmosphere at $1200^{\circ} \mathrm{C}$ for $1 \mathrm{~h}$ with heating and cooling rates of $5{ }^{\circ} \mathrm{C} \mathrm{min}{ }^{-1}$. Fig. 1 shows a scheme of the coating process.

\subsection{Characterization of the coatings}

The microstructure of the polished and unpolished Ti substrates and the resulting TiN coatings was investigated by Scanning electron

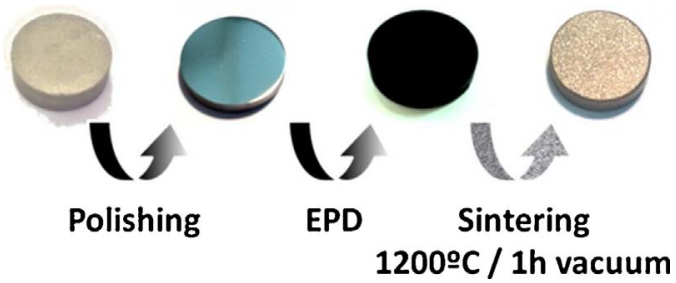

Fig. 1. Scheme based on the aspect of Ti specimens: as-prepared, polished, after TiN deposition by EPD and after sintering at $1200{ }^{\circ} \mathrm{C} / 1 \mathrm{~h}$.

microscopy (SEM) using a S-4700 microscope (Hitachi, Japan). The roughness of the coatings was measured using a profilometer (Surtronic $3+$ instrument, Taylor Hobson) and each profile was recorded five times per samples. The crystallographic composition of the coatings was analyzed by X-ray diffraction (XRD, Bruker D8 Advance) using a $\mathrm{Cu} \mathrm{K} \alpha$ radiation, where the scanning angular $(2 \theta)$ was varied from $20^{\circ}$ to $70^{\circ}$ and the scanning speed was $2^{\circ} \min ^{-1}$. The characterization of the composition of the coating after sintering was completed by using confocal Raman microscopy coupled with an atomic force microscopy (AFM) instrument (WiTec alpha300R) with a Nd:YAG laser excitation at $532 \mathrm{~nm}$ and a $100 \times$ objective.

The nanohardness of the new surfaces was explored using a CETR Bruker nanoindenter fitted with a Berkovich diamond tip of $100 \mathrm{~nm}$ radius, increasing the load from 0 to $500 \mathrm{mN}$. The hardness and elastic modulus were obtained from the curves using the Oliver-Pharr method. The hardness of the samples was also tested at the specimens along the interface Ti-TiN by Vickers method with a $200 \mathrm{~N}$ load. Indentations were repeated 10 times on different areas to show the evolution of the hardness from the surface to the center of the sample.

The corrosion resistance of the coated Ti specimens was tested determining polarization curves. A saturated calomel electrode (SCE) and a Pt wire was used as the reference electrode and counter electrode respectively, while the un-coated and coated Ti was the working electrode. A $3.5 \mathrm{wt} . \% \mathrm{NaCl}$ solution was used as electrolyte. The polarization of the samples was carried out in the range of -100 to $1000 \mathrm{mV}$ above the open-circuit potential at $0.5 \mathrm{mV} \mathrm{s}^{-1}$.

\section{Results}

\subsection{Microstructure of as-deposited and deposited coatings}

XRD spectra of TiN coating deposited on as-prepared and polished Ti substrates after sintering at $1200{ }^{\circ} \mathrm{C}$ are shown in Fig. 2a and b, respectively. In both cases the substrate peaks are denoted as Ti. All reflections correspond to the hexagonal lattice of the Ti (JCPDS No. 00044-1294). In the case of TiN coating on as-prepared substrate (Fig. 2a), the peaks which correspond to TiN can be slightly identified among those of the Ti indicating a low presence of TiN. The peaks positions of TiN were compared with the JCPDS file No. 00-038-1420 and the corresponding planes were indexed. Oppositely, the high intensity of the X-ray diffraction pattern of TiN in the analysis of the coating deposited on polished substrates evidences the clear existence of a TiN layer (Fig. 2b). One intense TiN (111) diffraction peak can be observed at $36.25^{\circ}$ which suggests the presence of the phase with $\mathrm{B} 1 \mathrm{NaCl}$ cubic structure. Comparing the XRD pattern of the TiN coating on the polished substrate with that of the as-received powders [24], a preferential orientation of TiN (111) can be identified, similarly to the TiN layers obtained by Subramanian et al. in 2011, and Cui et al. in 2017 $[7,27]$, both processed by magnetron sputtering. The comparative analysis of both TiN spectra suggests that TiN can moderately dissolve nitriding the Ti substrate during sintering. Unpolished substrates favor nitrogen diffusion throughout $\mathrm{Ti}$ probably due to their porous and rough surface, and the TiN partially vanishes. In fact, energy-dispersive $\mathrm{X}$-ray spectroscopy analysis (not shown here) of the TiN coated as- 


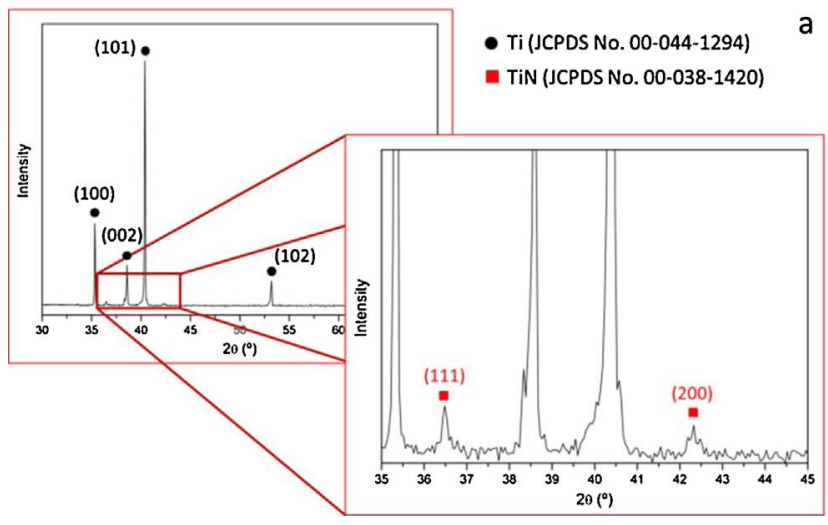

a

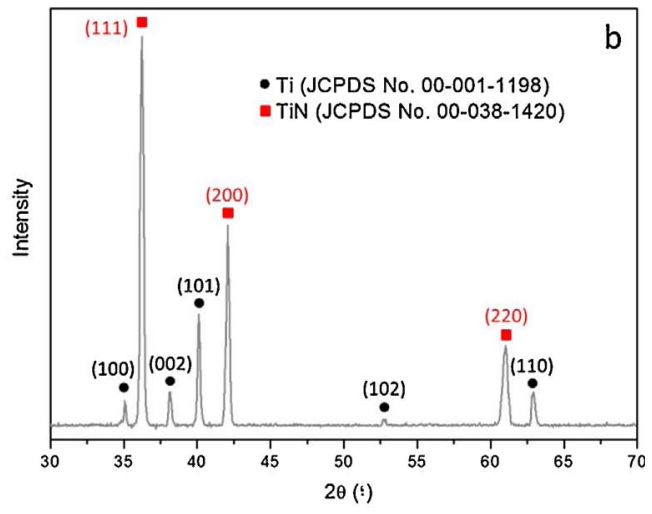

Fig. 2. XRD patterns of TiN coating on a) as-prepared and b) polished Ti substrate after sintering at $1200{ }^{\circ} \mathrm{C}$ for $1 \mathrm{~h}$ in vacuum.

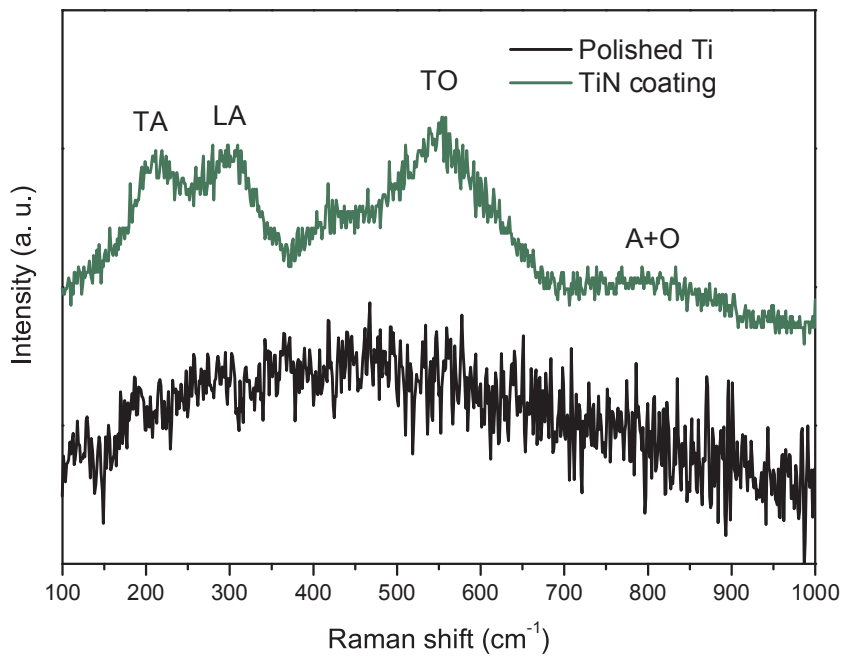

Fig. 3. Raman spectrum in the region $100-1000 \mathrm{~cm}^{-1}$ obtained from polished Ti substrate and TiN coating deposited onto polished Ti with the TA (transversal acoustic), LA (longitudinal acoustic), TO (transversal optic) and A $+\mathrm{O}$ (acoustic + optic) modes.

prepared substrate determine the existence of a nitrogen gradient in the Ti specimen supporting the Ti bulk piece nitriding. Fig. 3 shows the Raman spectra of Ti substrate and TiN film on polished Ti. The polished Ti substrate has not any peaks in the entire studied region due to the absence of nitrogen atoms in the structure. However, TiN films present low frequency peaks below $400 \mathrm{~cm}^{-1}$ caused by acoustical phonons and a high frequency mode around $540 \mathrm{~cm}^{-1}$.

The intensities of the acoustic modes are comparable to the optical part of the spectra due to the local $\mathrm{O}_{\mathrm{h}}$ symmetry with substitutional impurity in a crystal with a $\mathrm{NaCl}$ structure like TiN. The selection rules of this impurity induced scattering indicate that the phonons are contributing where the defect is at rest, in such a way that the intensities of the optical and acoustic modes are comparable [28]. H.C. Barshilia et al. [29] reported the Raman spectra of TiN single layers. They found that $\mathrm{TiO}_{2}$ in rutile phase presents two strong peaks at 444 and $518 \mathrm{~cm}^{-1}$, while TiN peaks are broader and are located at 242 and $562 \mathrm{~cm}^{-1}$. In this work, the strong peaks at $215 \mathrm{~cm}^{-1}$ (TA, transversal acoustic), $300 \mathrm{~cm}^{-1}$ (LA, longitudinal acoustic) and $545 \mathrm{~cm}^{-1}$ (TO, transversal optic) are associated with the first order Raman scattering of TiN. It indicates the absence of $\mathrm{TiO}_{2}$ in rutile phase by oxydation of TiN and confirms the presence of TiN phase in the coating as evidenced by XRD.

Fig. 4 shows the SEM micrographs evidencing the surface morphologies of the as-sintered Ti substrate (Fig. 3a) and after the polishing (Fig. 3b) and coating processes (Fig. 3c) following the scheme in Fig. 1. Some dimples or pores can be observed in the surface of the as-prepared substrates which are characteristic of the surface finishing of untreated Ti specimens processed by powder metallurgy. The morphology of the polished substrate changes and a smooth surface can be observed. When TiN is deposited by EPD, the coating covers the polished surface and a consolidated and dense microstructure can be then observed. The surface roughness of as-prepared and polished titanium substrates was measured by profilometry and compared with the surface roughness of TiN coating deposited onto polished titanium (Fig. 5).

Roughness profiles changed drastically depending on the Ti surface finishing. Profiles were analyzed to determine the roughness parameters collected in Table 1: the roughness average, $R_{a}$, the maximum profile peak height, $R_{t}$, and the average maximum profile, $R_{z}$.

As expected, significant differences are evidenced between the roughness values of both Ti finishing. The as-prepared Ti shows a spiky texture with a maximum roughness of $13.467 \mu \mathrm{m}$ compared to $0.948 \mu \mathrm{m}$ for polished titanium substrate which indicates the effectiveness of the polishing process. Those differences in roughness could explain the proposed effect of Ti nitriding explained above, based on the slight signal of the XRD spectrum of the TiN film deposited on the as-prepared substrate (Fig. 2). The lower exposed surface of the polished finishing decreases the surface reactivity avoiding the diffusion of nitrogen from the TiN layer to the Ti microstructure.

In the case of the TiN coating a wavy texture is observed in the micrographs (Fig. 3c) with a submicronic roughness average $\left(R_{a}=0.518 \pm 0.022 \mu \mathrm{m}\right)$ which gives an idea of the homogeneity of the film as a result of the uniform electrophoretic deposition of TiN nanoparticles. Moreover the maximum profile average $\left(R_{\mathrm{z}}=6.743 \pm 0.422 \mu \mathrm{m}\right)$ is close to the maximum profile peak height $\left(R_{t}=5.090 \pm 0.466 \mu \mathrm{m}\right)$ indicating that there is not any preferential zone of nanoparticles deposition at the whole Ti surface. In fact, the mean particle size of TiN powder is $26-32 \mathrm{~nm}$, but agglomerates of $\sim 200 \mathrm{~nm}$ can be observed in FE-SEM exploration [24]. This evidence verifies the optimal homogeneous growth of the TiN coating deposited by EPD [30]. However, EPD coatings are rougher than those obtained by PVD [23] or nitriding [10] and high roughness increase the exposed surface, which could be interesting in processes such as biomedical and catalysis applications but would have adverse consequences in its protective character.

Nanoindentation hardness and elastic modulus of TiN deposited on polished Ti-substrate were also measured. Hardness and elastic modulus of tested surfaces were obtained from load-unload-displacement curves. Measurements were repeated up to 30 times by specimen and the results are summarized in Table 2. Fig. 6a shows the representative load-displacement curves measured for the substrate and TiN coating, respectively. The curves present a homogeneous and continuous variation, which indicates that no cracks appear during the loading. Fig. $6 \mathrm{~b}$ shows the image of a multiple indents on polished Ti-substrate where the footprint of the tip is clearly visible. In the case of TiN-coating, the footprint indentations in Fig. 6c are substituted by a pseudo-plastic deformation and their traces are not so remarkable. 

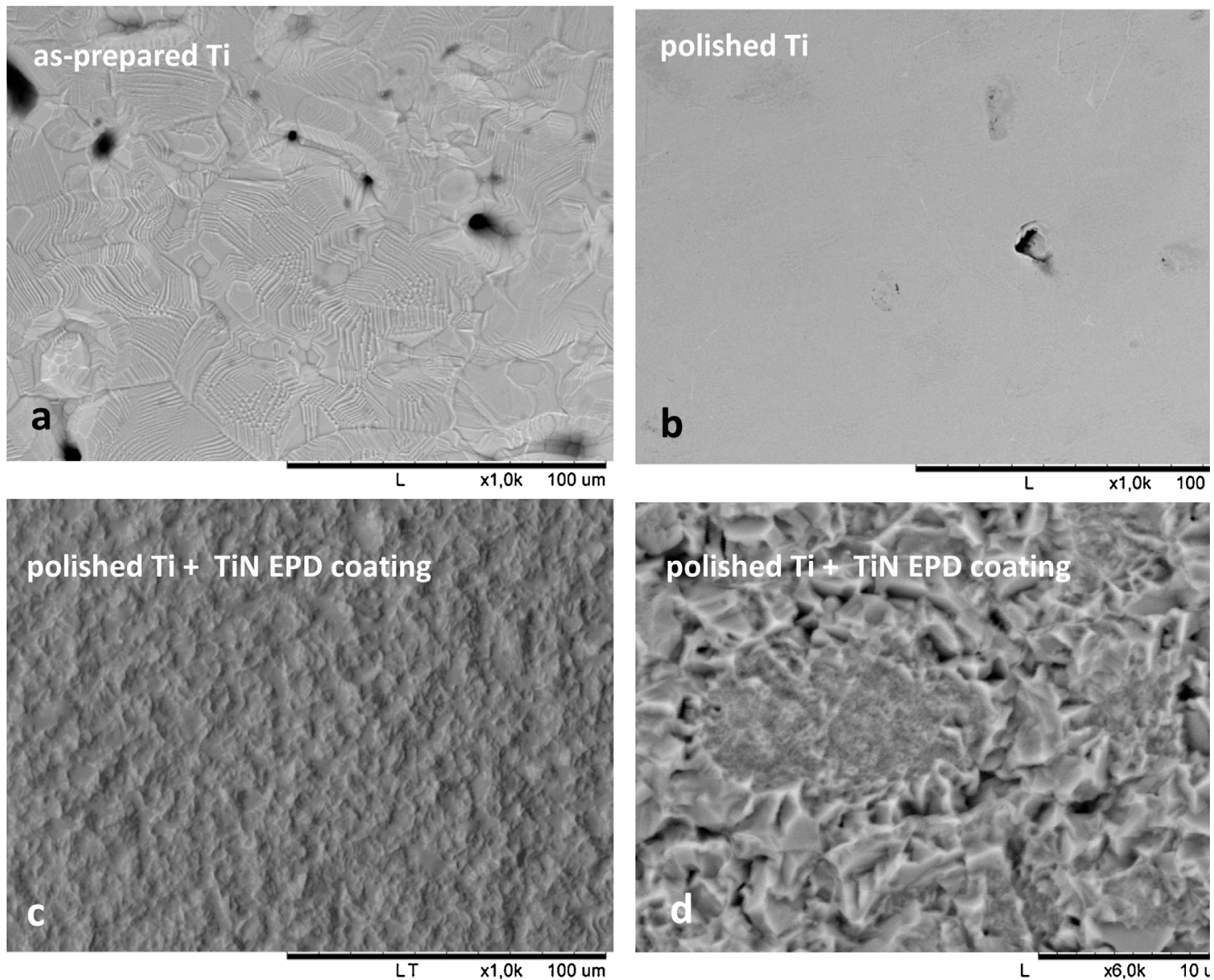

Fig. 4. SEM surface micrographs of Ti substrates: a) as-prepared, b) after polishing and c,d) TiN coatings at different magnifications.

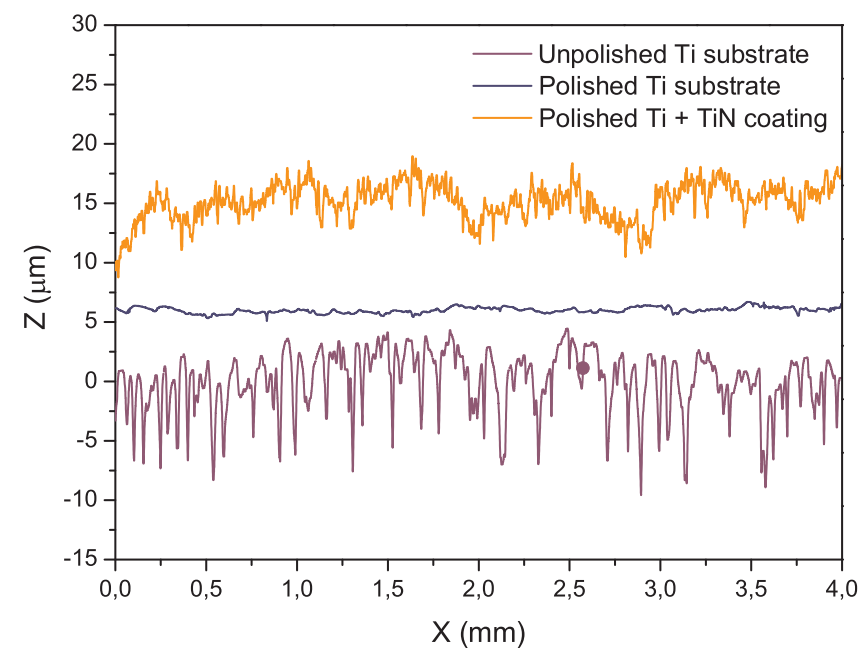

Fig. 5. Profilograms of unpolished and polished Ti-substrate compared to TiN coating on polished Ti-substarate.

Table 1

Surface roughness amplitude parameters $\left(R_{a}, R_{t}\right.$ and $\left.R_{z}\right)$ of as-prepared and polished Ti substrates, and TiN coating on polished Ti.

\begin{tabular}{llll}
\hline & $\mathrm{R}_{\mathrm{a}}(\mu \mathrm{m})$ & $\mathrm{R}_{\mathrm{t}}(\mu \mathrm{m})$ & $\mathrm{R}_{\mathrm{z}}(\mu \mathrm{m})$ \\
\hline As-prepared Ti & $1.283 \pm 0.172$ & $11.787 \pm 2.514$ & $13.467 \pm 3.234$ \\
Polished Ti & $0.059 \pm 0.008$ & $0.719 \pm 0.197$ & $0.948 \pm 0.097$ \\
TiN coating & $0.518 \pm 0.022$ & $5.090 \pm 0.466$ & $6.743 \pm 0.422$ \\
\hline
\end{tabular}

Table 2

Mechanical properties of the polished Ti substrate and TiN coating.

\begin{tabular}{lll}
\hline & Ti substrate & TiN coating \\
\hline Hardness & $2.8-3.8 \mathrm{GPa}$ & $\begin{array}{l}6.5-8.5 \mathrm{GPa} \\
157 \mathrm{GPa}\end{array}$ \\
\hline
\end{tabular}

The average hardness of polished Ti-substrate ranges $2.8-3.8 \mathrm{GPa}$ increasing for TiN coating $(6.5-7.5 \mathrm{GPa})$. Similarly occurs with the elastic modulus that improves from $118 \mathrm{GPa}$ to $157 \mathrm{GPa}$ with the coating. The maximum penetration depth for the Ti substrate was $2.7 \mu \mathrm{m}$ while for the TiN coating was $1.5 \mu \mathrm{m}$. The $7-8 \mu \mathrm{m}$ thick TiN coating prepared by EPD (shown later in Fig. 7) has nanohardness values not far from those reported for sputtered TiN coatings of around $5 \mu \mathrm{m}(10.2 \pm 1.2 \mathrm{GPa})$ [7] and those of the difussion layers of 5-30 $\mu \mathrm{m}$ obtained by nitriding Ti6Al4 V substrates (8.5-11.1 GPa) [10]. On the other hand, although the value of elastic modulus is lower than the regular value of TiN ( $\sim 280 \mathrm{GPa})$ it is higher than that of the coated material (Ti substrate). The low modulus of the TiN coatings could be related to the difusion of nitrogen throughout the Ti during the thermal treatment, which could alteres its stoichiometry and be reflected in its surface mechanical behaviour [7].

Fig. 7 plots the depth profile of indentation over the cross section of the TiN layer, schematicing the variation of the hardness and elastic modulus as a function of depth. Vickers hardness was measured for a $200 \mathrm{~N}$ load along the cross-section of the TiN-Ti material. The values of hardness are plotted as a function of depth: 0 (surface), 12, 20, 40 and $85 \mu \mathrm{m}$. It was found that the hardness decreases from the surface of the TiN coating to the bulk Ti substrate. Hardness varies gradually from 4.1 to $2.2 \mathrm{GPa}$ supporting the describing nitrogen diffusion phenomenon. 

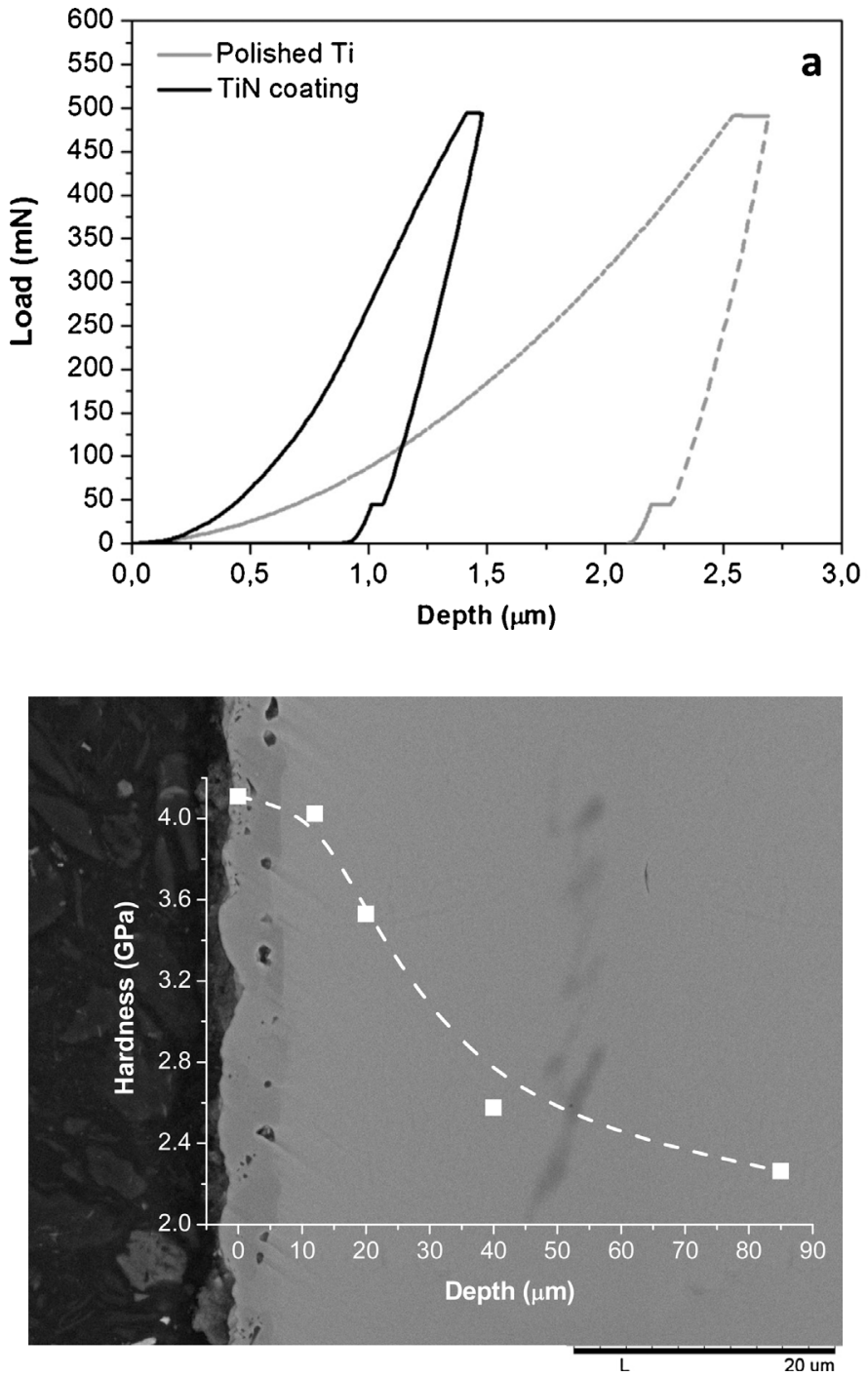

Fig. 7. Vickers hardness of TiN-polished Ti along the interface.

These values are complementary to the nanohardness characterization of the TiN surface and confirm the improvement of the mechanical properties, demonstrating that roughness doesńt compromise the protective character of the TiN coating shaped by EPD.

Finally, the corrosion behavior of polished Ti substrate and TiN coating was evaluated by electrochemical measurements. The potentiodynamic polarization curves of the coating and substrate determined in $3.5 \% \mathrm{NaCl}$ are shown in Fig. 8 . The corrosion potential ( $\mathrm{E}_{\text {corr }}$ ) shifts towards the positive side, from $-55 \mathrm{mV}$ to $40 \mathrm{mV}$, with the TiN coating, while the corrosion current density, determined by the intersection of the extrapolation of Tafel curves linear, is reduced more than one order of magnitude to $9.4 \mathrm{E}^{-9} \mathrm{Acm}^{-2}$ (Table 3). The reduction of the corrosion current density and the increase of the corrosion potential indicate a significant enhancement of the corrosion resistance by deposition of a TiN coating. The good corrosion resistance is largely due to the formation of very stable and highly adherent film on the surface. However, the shape of the polarization curves for TiN and Ti keeps similar indicating that despite the protective behavior of TiN, the coating shows a partial pitting corrosion associated with the presence of punctual heterogeneities or porous close to the TiN surface (Fig. 7).

The protective efficiency $\mathrm{P}(\%)$ of the coating can also be determined by using the equation:

$\mathrm{P}=\left(1-\mathrm{i}_{\text {corr }} / \mathrm{i}^{0}{ }_{\text {corr }}\right) * 100 \%$

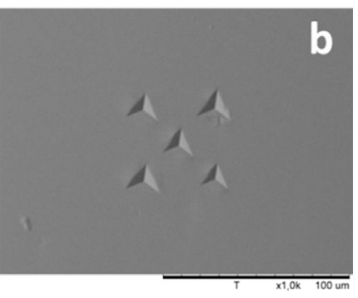

Fig. 6. Nano-indentation load-depth curves of polished Ti-substrate and TiN coated on polished Tisubstrate a) and the optical images of indent by a Berkovich diamond tip on b) polished Ti-substrate and c) TiN coated on polished Ti-substrate.
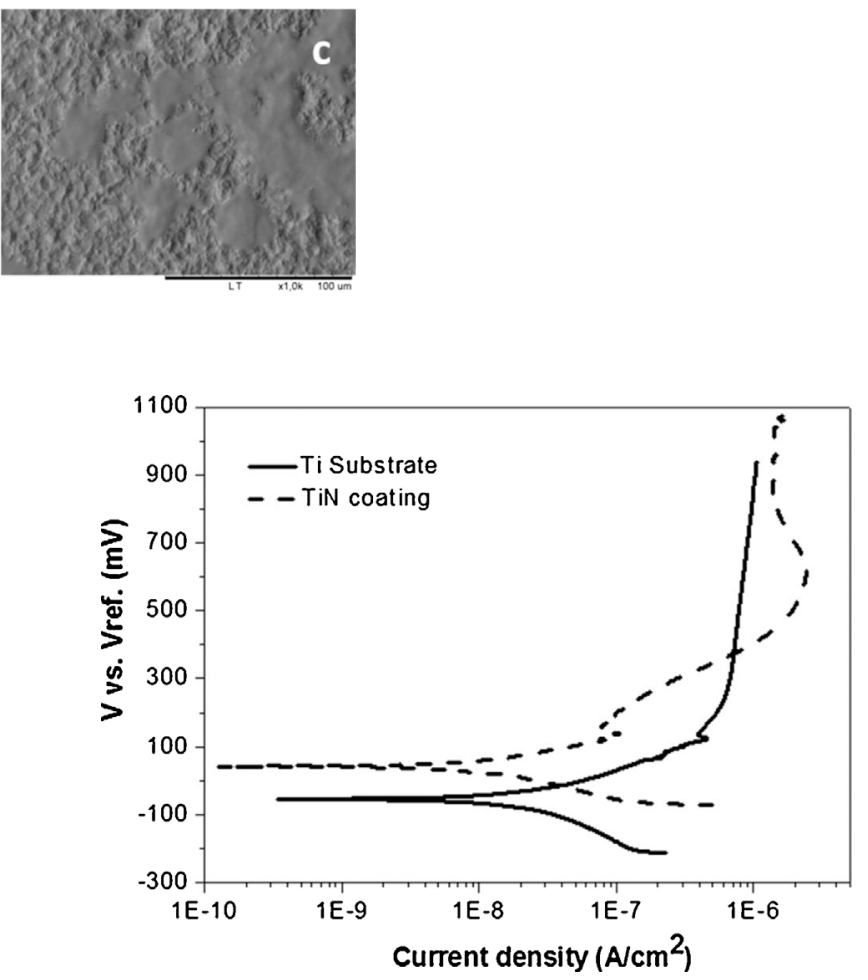

Fig. 8. Potentiodynamic polarization curves of a TiN single coating and a polished Tisubstrate in simulated sea water (3.5 wt.\% $\mathrm{NaCl}$ solution).

Table 3

Potentiodynamic polarization results of Ti-substrate and TiN layer coating.

\begin{tabular}{llll}
\hline & $\mathrm{E}_{\text {corr }}(\mathrm{mV})$ & $\mathrm{i}_{\text {corr }}\left(\mathrm{A} \mathrm{cm}^{-2}\right)$ & $\mathrm{P}(\%)$ \\
\hline Ti substrate & -55 & $5.5 \mathrm{E}-8$ & - \\
TiN coating & 41 & $9.4 \mathrm{E}-9$ & 82 \\
\hline
\end{tabular}

where $\mathrm{i}_{\text {corr }}$ and $\mathrm{i}_{\text {corr }}^{0}$ correspond to the corrosion current density of the TiN coatings and Ti substrate, respectively. The high protective efficiency of TiN coatings (82\%) demonstrates that they effectively increase the corrosion resistance of the substrate in $\mathrm{NaCl}$ solutions. Few corrosion studies of TiN coatings covering $\mathrm{Ti}$ and Ti-alloys have been described in the literature $[8,10]$, pointing up the lack of improvement assessment of the corrosion resistance refereed to the Ti substrate. Up to our knowledge, only the corrosion study of TiN coatings deposited by PVD on a 304 AISI stainless steel provides a more effective corrosion protection in $\mathrm{NaCl}$ solutions [23].

Although further investigations are still needed to gets an optimized combination of coatings hardness and corrosion resistance, increasing for example the deposited thickness, these preliminary mechanical and electrochemical results shows that EPD coatings of TiN can be proposed for wear protection of metallic implants.

\section{Conclusions}

The efficient protective behavior of TiN coatings shaped by EPD 
covering Ti substrates was demonstrated. Polished surface finishing of dense powder metallurgic Ti favors the uniform deposition and consolidation of TiN nanoparticles by EPD. The obtained homogeneous TiN coatings have a wavy texture and submicronic roughness average $\left(R_{a}=0.518 \pm 0.022 \mu \mathrm{m}\right)$ after sintering at $1200{ }^{\circ} \mathrm{C} / 1 \mathrm{~h}$ in vacuum. Nitrogen diffusion is partially avoided by reducing the reaction surface by polishing, preventing the TiN coating dissolution in the Ti substrate. The nitrogen diffusion that still takes place from the TiN film to the Ti bulk piece during sintering in polished substrates, promotes the formation of a cohesive layer of 7-8 $\mu \mathrm{m}$ in thickness, well adhered, which deserves a relevant improvement of the surface average hardness and the elastic modulus, referred to the Ti substrate. Nanohardness values increases up to 6.5-8.5 GPa of the TiN surface from 2.8-4.8 GPa measured for polished Ti. In the same line, the corrosion current density is reduced more than one order of magnitude to $9.4 \mathrm{E}^{-9} \mathrm{Acm}^{-2}$, which implies a protective efficiency of $82 \%$ refereed to the corrosion resistance of the polished Ti substrate. This preliminary result shows the possibility of using this material as metallic implants.

The evolution of Vickers hardness determined at the cross section of the TiN/Ti specimen supports the described Ti nitriding phenomenon. Nitrogen diffusion steps up when the TiN coating was deposited on asprepared $\mathrm{Ti}$, while mechanical tests suggest the beneficial effect of diffusion in the effective joining between the TiN powder compacted by EPD and the dense metallic substrate during the coating consolidation at such a low sintering temperature.

\section{Acknowledgements}

The authors acknowledge the support to the projects S2013/MIT2862 and MAT2015-70780-C4-1.

\section{References}

[1] X. b Liu, P.K. Chu, C. Ding, Surface modification of titanium alloys, and related materials for biomedical applications, Mater. Sci. Eng. R Rep. 47 (2004) 49-121.

[2] M. Geetha, A.K. Singh, R. Asokamani, A.K. Gogia, Ti based biomaterials, the ultimate choice for orthopaedic implants - a review, Prog. Mater. Sci. 54 (2009) 397-425.

[3] Y. Kirmanidou, M. Sidira, M.-E. Drosou, V. Bennani, A. Bakopoulou, A. Tsouknidas, et al., New Ti-Alloys and Surface Modifications to Improve the Mechanical Properties and the Biological Response to Orthopedic and Dental Implants: a review, Biomed. Res. Int. 2016 (2016).

[4] C. Martini, L. Ceschini, A comparative study of the tribological behaviour of PVD coatings on the Ti6Al4 V alloy, Tribol. Int. 44 (2011) 297-308.

[5] R. Ali, M. Sebastiani, E. Bemporad, Influence of Ti-TiN multilayer PVD-coatings design on residual stresses and adhesion, Mater. Des. 75 (2015) 47-56.

[6] W. Österle, D. Klaffke, M. Griepentrog, U. Gross, I. Kranz, C. Knabe, Potential of wear resistant coatings on Ti6Al4 $\mathrm{V}$ for artificial hip joint bearing surfaces, Wear 264 (2008) 505-517.

[7] W. Cui, G. Qin, J. Duan, H. Wang, A graded nano-TiN coating on biomedical Ti alloy: low friction coefficient, good bonding and biocompatibility, Mater. Sci. Eng. C. 71 (2017) 520-528.

[8] B. Subramanian, C.V. Muraleedharan, R. Ananthakumar, M. Jayachandran, A comparative study of titanium nitride (TiN) titanium oxy nitride (TiON) and titanium aluminum nitride (TiAlN), as surface coatings for bio implants, Surf. Coat. Technol. 205 (2011) 5014-5020.

[9] M.K. Tripathi, V.B. Singh, H.K. Singh, Structure and properties of electrodeposited functional Ni-Fe/TiN nanocomposite coatings, Surf. Coat. Technol. 278 (2015) $146-156$.

[10] I.M. Pohrelyuk, V.M. Fedirko, O.V. Tkachuk, R.V. Proskurnyak, Corrosion resistance of Ti6Al4 V alloy with nitride coatings in Ringer's solution, Corros. Sci. 66 (2013) 392-398.

[11] M. Li, J. Huang, Y.Y. Zhu, Z.G. Li, Effect of heat input on the microstructure of insitu synthesized TiN-TiB/Ti based composite coating by laser cladding, Surf. Coat. Technol. 206 (2012) 4021-4026.

[12] S.A. Tsipas, M.R. Vázquez-Alcázar, E.M.R. Navas, E. Gordo, Boride coatings obtained by pack cementation deposited on powder metallurgy and wrought Ti and Ti-6Al-4 V, Surf. Coat. Technol. 205 (2010) 2340-2347.

[13] T.R. Rautray, R. Narayanan, K.H. Kim, Ion implantation of titanium based biomaterials, Prog. Mater. Sci. 56 (2011) 1137-1177.

[14] J.A. Lewis, Colloidal processing of ceramics, J. Am. Ceram. Soc. 83 (2000) 2341-2359.

[15] W.M. Sigmund, N.S. Bell, L. Bergstrom, Novel powder-processing methods for advanced ceramics, J. Am. Ceram. Soc. 83 (2000) 1557-1574.

[16] Z. Gonzalez, B. Ferrari, A.J. Sanchez-Herencia, A. Caballero, J. Morales, Relevance of the semiconductor microstructure in the pseudocapacitance of the electrodes fabricated by EPD of binder-free beta-Ni(OH)(2) nanoplatelets, J. Electrochem. Soc. 162 (2015) D3001-D3012.

[17] M. Verde, A.C. Caballero, Y. Iglesias, M. Villegas, B. Ferrari, Electrophoretic deposition of flake-shaped ZnO nanoparticles, J. Electrochem. Soc. 157 (2010) H55-H59.

[18] S. PalDey, S. Deevi, Single layer and multilayer wear resistant coatings of (Ti,Al)N: a review, Mater. Sci. Eng. A 342 (2003) 58-79.

[19] M. Das, V.K. Balla, D. Basu, I. Manna, T.S. Sampath Kumar, A. Bandyopadhyay, Laser processing of in situ synthesized TiB-TiN-reinforced Ti6Al4 V alloy coatings, Scr. Mater. 66 (2012) 578-581.

[20] Y.H. Cheng, T. Browne, B. Heckerman, C. Bowman, V. Gorokhovsky, E.I. Meletis, Mechanical and tribological properties of TiN/Ti multilayer coating, Surf. Coat. Technol. 205 (2010) 146-151.

[21] V. Rupetsov, G. Mishev, S. Dishliev, V. Kopanov, V. Chitanov, L. Kolaklieva, et al., Increasing in the wear resistance of injection molds made of 1.2343 steel using Ti/ TiN/TiCN/nc-TiCN:a-C/nc-TiC:a-C/a-C nanocomposite coating, IOP Conf. Ser. Mater. Sci. Eng. 174 (2017) 12064.

[22] V.K. Balla, A. Bhat, S. Bose, A. Bandyopadhyay, Laser processed TiN reinforced Ti6Al4 V composite coatings, J. Mech. Behav. Biomed. Mater. 6 (2012) 9-20.

[23] A.Y. Adesina, Z.M. Gasem, A. Madhan Kumar, Corrosion resistance behavior of single-layer cathodic arc PVD nitride-base coatings in $1 \mathrm{M} \mathrm{HCl}$ and 3.5 pct $\mathrm{NaCl}$ solutions, Metall. Mater. Trans. B 48 (2017) 1321-1332.

[24] C. Mendoza, Z. González, Y. Castro, E. Gordo, B. Ferrari, Improvement of TiN nanoparticles EPD inducing steric stabilization in non-aqueous suspensions, J. Eur. Ceram. Soc. 36 (2016) 307-317.

[25] J. Ureña, C. Mendoza, B. Ferrari, Y. Castro, S.A. Tsipas, A. Jiménez-Morales, et al., Surface modification of powder metallurgy titanium by colloidal techniques and diffusion processes for biomedical applications, Adv. Eng. Mater. 19 (6) (2016) 1600207.

[26] C. Mendoza, Z. González, Y. Castro, B. Ferrari, Dispersion and stabilization of TiN and TiC nanoparticles in organic suspensions, Key Eng. Mater. 654 (2015) 203-207.

[27] B. Subramanian, R. Ananthakumar, M. Jayachandran, Structural and tribological properties of reactive magnetron sputtered titanium/titanium nitride (Ti/TiN) multilayered coatings, Surf. Coat. Technol. 205 (2011) 3485-3492.

[28] C.C. Chen, N.T. Liang, W.S. Tse, I.Y. Chen, J.G. Duh, Raman spectra of titanium nitride thin films, Chin. J. Phys. 32 (1994) 205-210.

[29] H.C. Barshilia, K.S. Rajam, Raman spectroscopy studies on the thermal stability of TiN, CrN TiAIN coatings and nanolayered TiN/CrN, TiAIN/CrN multilayer coatings, J. Mater. Res. 19 (2004) 3196-3205.

[30] I. Gonzalo-Juan, J.A. Escribano, Y. Castro, A.J. Sanchez-Herencia, J.L.G. Fierro, B. Ferrari, One-pot manufacture of nanoparticle-based films in aqueous media via an electric field-driven assembly process, Green Chem. 16 (2014) 3286-3296. 